\title{
Assessment of tissue perfusion of pancreatic cancer as potential imaging biomarker by means of Intravoxel incoherent motion MRI and CT perfusion: correlation with histological microvessel density as ground truth
}

Philipp Mayer ${ }^{1 *}$ D, Franziska Fritz ${ }^{1}$, Marco Koell ${ }^{1}$, Stephan Skornitzke¹, Frank Bergmann², Matthias M. Gaida ${ }^{3}$, Thilo Hackert ${ }^{4}$, Klaus Maier-Hein ${ }^{5}$, Frederik B. Laun ${ }^{6,7}$, Hans-Ulrich Kauczor ${ }^{1}$, Lars Grenacher ${ }^{1,8}$, Miriam Klauß ${ }^{1+}$ and Wolfram Stiller ${ }^{1+}$

\footnotetext{
Abstract

Background/objectives: The aim of this study was to compare intravoxel incoherent motion (IVIM) diffusion weighted (DW) MRI and CT perfusion to assess tumor perfusion of pancreatic ductal adenocarcinoma (PDAC).

Methods: In this prospective study, DW-MRI and CT perfusion were conducted in nineteen patients with PDAC on the day before surgery. IVIM analysis of DW-MRI was performed and the parameters perfusion fraction $f$, pseudodiffusion coefficient $D^{*}$, and diffusion coefficient $D$ were extracted for tumors, upstream, and downstream parenchyma. With a deconvolution-based analysis, the CT perfusion parameters blood flow (BF) and blood volume (BV) were estimated for tumors, upstream, and downstream parenchyma. In ten patients, intratumoral microvessel density $\left(\mathrm{MVD}_{\text {tumor }}\right)$ and microvessel area ( $\left(\mathrm{MVA}_{\text {tumor }}\right)$ were analyzed microscopically in resection specimens. Correlation coefficients between IVIM parameters, CT perfusion parameters, and histological microvessel parameters in tumors were calculated. Receiver operating characteristic (ROC) analysis was performed for differentiation of tumors and upstream parenchyma.

(Continued on next page)
}

\footnotetext{
* Correspondence: Philipp.Mayer@med.uni-heidelberg.de

${ }^{\dagger}$ Miriam Klauß and Wolfram Stiller contributed equally to this work.

${ }^{1}$ Clinic for Diagnostic and Interventional Radiology (DIR), Heidelberg University Hospital, Im Neuenheimer Feld 420, 69120 Heidelberg, Germany Full list of author information is available at the end of the article
}

(c) The Author(s). 2021 Open Access This article is licensed under a Creative Commons Attribution 4.0 International License, which permits use, sharing, adaptation, distribution and reproduction in any medium or format, as long as you give appropriate credit to the original author(s) and the source, provide a link to the Creative Commons licence, and indicate if changes were made. The images or other third party material in this article are included in the article's Creative Commons licence, unless indicated otherwise in a credit line to the material. If material is not included in the article's Creative Commons licence and your intended use is not permitted by statutory regulation or exceeds the permitted use, you will need to obtain permission directly from the copyright holder. To view a copy of this licence, visit http://creativecommons.org/licenses/by/4.0/. The Creative Commons Public Domain Dedication waiver (http://creativecommons.org/publicdomain/zero/1.0/) applies to the data made available in this article, unless otherwise stated in a credit line to the data. 
(Continued from previous page)

Results: $f_{\text {tumor }}$ significantly positively correlated with $\mathrm{BF}_{\text {tumor }}(r=0.668, p=0.002)$ and $\mathrm{BV}_{\text {tumor }}(r=0.672, p=0.002)$. There were significant positive correlations between $f_{\text {tumor }}$ and $\mathrm{MVD}_{\text {tumor }} / \mathrm{MVA}_{\text {tumor }}(r \geq 0.770, p \leq 0.009)$ as well as between $\mathrm{BF}_{\text {tumor }}$ and $\mathrm{MVD}_{\text {tumor }} / \mathrm{MVA}_{\text {tumor }}(r \geq 0.697, p \leq 0.025)$. Correlation coefficients between $f_{\text {tumor }}$ and $M V D_{\text {tumor }} / M A_{\text {tumor }}$ were not significantly different from correlation coefficients between BF tumor and $M V D_{\text {tumor }}$ $\mathrm{MVA}_{\text {tumor }}(p \geq 0.400)$. Moreover, $f, B F, B V$, and permeability values (PEM) showed excellent performance in distinguishing tumors from upstream parenchyma (area under the ROC curve $\geq 0.874$ ).

Conclusions: The study shows that IVIM derived $f_{\text {tumor }}$ and $C T$ perfusion derived $B F_{\text {tumor }}$ similarly reflect vascularity of PDAC and seem to be comparably applicable for the evaluation of tumor perfusion for tumor characterization and as potential quantitative imaging biomarker.

Trial registration: DRKS, DRKS00022227, Registered 26 June 2020, retrospectively registered. https://www.drks.de/ drks_web/navigate.do?navigationld=trial. HTML\&TRIAL_ID=DRKS00022227.

Keywords: Pancreatic ductal adenocarcinoma, X-ray computed tomography, Diffusion magnetic resonance imaging, Microvessels

\section{Introduction}

Pancreatic ductal adenocarcinoma (PDAC) is notorious for its exceptionally high mortality with an estimated global mortality rate of $98 \%$ [1]. It has been reported that the complex tumor biology with the distinct microenvironment of the cancer has important influence on the prognosis of PDAC [2-4]. One of the factors which are known to be associated with prognosis in malignomas is tumor vascularity quantified histologically by the intratumor microvessel density (i.e. number of microvessels per tumor area, MVD). In various studies on PDAC, high MVD was associated with higher risk for liver and lymph node metastases as well as short survival time [5-12].

Tissue perfusion is regarded as a non-invasive marker for tumor vascularity and has been evaluated as biomarker of drug action in early phase trials for the treatment of various solid tumors [13], including PDAC [14]. Moreover, tissue perfusion was reported useful for the differentiation of local recurrence from unspecific postoperative alterations after PDAC resection [15].

For measurement of tumor tissue perfusion, the intravoxel incoherent motion (IVIM) model for diffusion weighted (DW) magnetic resonance imaging (MRI) as well as computed tomography (CT) perfusion have gained increasing interest during the past years. The IVIM model enables to extract parameters of both pure extravascular molecular diffusion and perfusion from DW MRI data [16]. CT perfusion measures tissue perfusion through the analysis of temporal changes in attenuation during the first pass of a bolus of iodinated contrast material [13].

Many previous studies have reported direct correlations between CT perfusion- derived parameters and MVD in other solid tumors [17], including pancreatic neuroendocrine neoplasms (PNEN) [18]. However, studies which correlate the histologically derived MVD with IVIM-derived parameters, or correlate IVIMderived parameters and CT perfusion- derived parameters are still quite rare. In a recent study, Klauß et al. showed a good correlation between the IVIM-derived perfusion fraction $f$ and the MVD in PDAC and PNEN [19]. A previous study failed to show a correlation between IVIM-derived parameters and CT perfusionderived parameters in hepatocellular carcinomas [20].

This raises the question if CT perfusion and IVIM MRI are comparably applicable for the assessment of tissue perfusion in solid tumors, or whether one method should be preferred over the other.

Therefore, the aim of our study was to compare IVIM DW MRI and CT perfusion to assess tumor perfusion of PDAC.

\section{Methods}

Study design, patient population and demographics

The study protocol of our prospective study was approved by our institutional review board and informed consent was obtained from the patients before the examination. Between August 2014 and July 2015, 23 patients (13 females and 10 males; mean age, 63.2 \pm 7.9 years [range: $50-79$ years]) with detection of a mass suspicious of PDAC in a previous CT and/or MRI and scheduled surgery with potentially curative intent were consecutively enrolled in our study. In all patients, indication for surgery had been made prior to and independently from the present study. The patients were scanned and evaluated prospectively, first with IVIM DW MRI, and second with CT perfusion, on the day before surgery.

Exclusion criteria were: general contraindications for the application of iodinated contrast agents, MR-unsafe foreign bodies, previous treatment for pancreatic 
carcinoma, inability to reproduce the breathing technique (see below), and/or denial of consent.

There was no histologically confirmed diagnosis at the time of inclusion in our study.

Out of the 23 total patients, the final histopathological diagnosis was PDAC in 20 patients, PNEN in one patient, anaplastic carcinoma in one patient, and massforming chronic pancreatitis in one patient. The three patients with histopathological diagnosis other than PDAC were excluded from our study. In one patient with PDAC the tumor area was missed in CT perfusion, therefore this patient was also excluded. CT perfusion and MRI diffusion could be evaluated in all remaining 19 patients. In 16 of these 19 patients, the tumor was located in the pancreatic head while 3 patients had a tumor in the pancreatic body and/ or tail. Among these 19 patients, resection was not possible and/or indicated due to infiltration of the superior mesenteric artery (SMA) in 1 patient, due to peritoneal metastases in 2 patients, and due to hepatic metastases in 1 patient. In these 4 patients in whom tumor resection was not performed, histological diagnosis was established from intraoperative biopsies from the part where the tumor infiltrated the SMA, or from the peritoneal/ hepatic metastases, respectively. In all 15 other patients, histological diagnosis was established from the resected primary tumor.

\section{Null hypothesis and alternative hypothesis}

The null hypothesis of the study is that the correlation of the perfusion fraction $f$ from IVIM DW MRI with MVD/ microvessel area (MVA) is not different from the correlation of blood flow (BF) from CT perfusion with MVD/ MVA. The alternative hypothesis of the study is that the correlation of $f$ with MVD/ MVA is different from the correlation of BF with MVD/ MVA.

\section{MR imaging and Post-processing}

MR imaging was performed using a $1.5 \mathrm{~T}$ scanner (Magnetom Avanto, Siemens Medical Solutions) with a 6element body-phased array coil and a 24-channel spine array coil. The pancreatic MR imaging protocol consisted of anatomic imaging sequences and diffusion weighted imaging (DWI) with 9 b-values $(0,50,100$, $150,200,300,400,600$, and $800 \mathrm{~s} / \mathrm{mm}^{2}$, summarized in Table 1). This combination of b-values was chosen since

Table 1 Parameters of MR imaging

\begin{tabular}{llllllll}
\hline $\begin{array}{l}\text { Sequence } \\
\text { type }\end{array}$ & $\begin{array}{l}\text { Breathing } \\
\text { position }\end{array}$ & Coverage & Orientation $\begin{array}{lll}\text { TR } \\
{[\mathrm{ms}]}\end{array}$ & $\begin{array}{l}\text { TE } \\
{[\mathrm{ms}]}\end{array}$ & $\begin{array}{l}\text { Acquisition } \\
\text { matrix }\end{array}$ & $\begin{array}{l}\text { Slice } \\
\text { thickness/ } \\
\text { gap [mm }]\end{array}$ & $\begin{array}{l}\text { Pixel } \\
\text { bandwidth } \\
{[\mathrm{Hz}]}\end{array}$
\end{tabular}

1) Anatomic MR imaging (performed in every patient)

\begin{tabular}{|c|c|c|c|c|c|c|c|}
\hline $\begin{array}{l}\text { T1-weighted } \\
\text { in/opposed } \\
\text { phase }\end{array}$ & $\begin{array}{l}\text { Inspiratory } \\
\text { breath- } \\
\text { hold }\end{array}$ & $\begin{array}{l}\text { Upper } \\
\text { abdomen }\end{array}$ & Transverse & 115 & $\begin{array}{l}2.27 \\
\text { and } \\
4.78\end{array}$ & $320 \times 272$ & $5 / 1$ \\
\hline $\begin{array}{l}\text { HASTE-IR T2- } \\
\text { weighted }\end{array}$ & $\begin{array}{l}\text { Inspiratory } \\
\text { breath- } \\
\text { hold }\end{array}$ & $\begin{array}{l}\text { Upper } \\
\text { abdomen }\end{array}$ & Coronal & 1000 & 80 & $256 \times 230$ & $6 / 0.6$ \\
\hline $\begin{array}{l}\text { HASTE T2- } \\
\text { weighted }\end{array}$ & $\begin{array}{l}\text { Expiratory } \\
\text { breath- } \\
\text { hold }\end{array}$ & $\begin{array}{l}\text { Upper } \\
\text { abdomen }\end{array}$ & Transverse & 680 & 95 & $320 \times 320$ & $4 / 0.4$ \\
\hline
\end{tabular}

2) Diffusion weighted MR imaging (performed in every patient)

\begin{tabular}{|c|c|c|c|c|c|c|c|c|}
\hline Ss-EPI & $\begin{array}{l}\text { Expiratory } \\
\text { breath- } \\
\text { hold }\end{array}$ & Pancreas & Transverse & $2200 \quad 58$ & $130 \times 92$ & $5 / 0.25$ & 2260 & $\begin{array}{l}\text { Pixel spacing: } 2.7 \mathrm{~mm} / 2.7 \mathrm{~mm} ; \\
\text { Number of acquired slices per b- } \\
\text { value: } 14 ; \\
\text { b-values }\left[\mathrm{s} / \mathrm{mm}^{2} \text { ] }\right]: 0,50,100,150, \\
200,300,400,600, \text { and } 800 ; \\
\text { Number of excitations: } 1 \text { for } \mathrm{b}=0 \\
\text { s/mm }{ }^{2}, 2 \text { for every other b-value; } \\
\text { Number of diffusion-encoding } \\
\text { gradient directions: } 3 ; \\
\text { K-space based parallel imaging } \\
\text { technique (GRAPPA); acceleration } \\
\text { factor: } 2 \text {; } \\
\text { Fat saturation technique: spectral } \\
\text { fat saturation. }\end{array}$ \\
\hline
\end{tabular}

The acquisition was separated into blocks $\left(b_{0}, b_{50}\right),\left(b_{0}, b_{100}\right) \ldots\left(b_{0}, b_{800}\right)$. Each block was acquired in a single breath-hold in expiration (TA $\left.=22 \mathrm{~s}\right)$ to avoid motion artifacts. No registration for correction of patient breathing-motion was applied.

The pancreatic MR imaging protocol consisted of 1) anatomic imaging sequences, and 2) diffusion weighted imaging with 9 b-values. An experienced radiologist directly involved in the study was always present during MR imaging. Abbreviations: n.a.: not applicable, fs: fat saturation, HASTE: Half-Fourier-Acquired Singleshot Turbo spin Echo, ss-EPI: Single-shot Echo-Planar Imaging, TE: echo time, TR: repetition time 
it had proven feasible for assessment of tissue perfusion in correlation to MVD in PDAC [19]. b-Values larger than $800 \mathrm{~s} / \mathrm{mm}^{2}$ were not chosen to minimize the kurtosis effect that becomes increasingly important at larger b-values [21].

MITK Diffusion software version 2017.07 (Medical Imaging Interaction Toolkit, DKFZ Heidelberg, www. MITK.org) was used for post-processing of DWI data [22]. Among several possible approaches described by Klaasen et al. [23], the following approach according to the IVIM model was chosen to calculate the perfusion fraction $f$, pseudodiffusion coefficient $\mathrm{D}^{*}$, and diffusion coefficient D, as previously described [19] (corresponding to Klaasen's model no. 3). The signal was averaged within a region of interest for each b-value. Then the equation

$$
\frac{S_{b}}{S_{0}}=(1-f) * \exp (-b * D)+f * \exp (-b *(D+D *))
$$

was fitted to the data. Here, $S_{b}$ stands for the signal with diffusion weighting and $S_{0}$ for the signal without diffusion weighting. Measurements at b-values greater than $170 \mathrm{~s} / \mathrm{mm}^{2}$ were used in a first step to estimate $\mathrm{f}$ and $\mathrm{D}$. $D^{*}$ was then calculated in a second step by using exhaustive search.

Quantitative analysis of DWI was performed independently by two radiologists with at least 5 years of experience in abdominal imaging each (P.M. and F.F.), blinded to the other radiologist's analysis and other patient information. Free-hand volumes of interest (VOIs) were drawn encompassing the tumor on DW images. The exact anatomical outline of the tumor was determined with the help of conventional CT images and/ or conventional biliary-pancreatic MR images. Calcifications (as detected by CT) and cystic/ necrotic tumor areas without enhancement (as detected by contrast enhanced CT) were excluded from the VOIs. When possible, upstream and downstream pancreatic parenchyma also was segmented by Reader 1 (P.M.). The reported values of $f, \mathrm{D}$, and $\mathrm{D}^{*}$ were derived from the generated VOIs in all cases.

\section{CT imaging and Post-processing}

Immediately after MR imaging, the patients were examined with CT imaging.

All examinations were carried out with a $2 \times 64$-slice CT scanner (Somatom Definition Flash; Siemens Medical Solutions), using the hydro-CT-technique [24]. Patients were placed on the CT table in an oblique, $30^{\circ}$, right-sided down position. The acquisition protocol is summarized in Table 2.

Perfusion data were analyzed with a body-perfusion CT-tool (Body-PCT, Siemens Medical Solutions) at a multimodality workplace with the syngo.via imaging software version VB 30 (Siemens Medical Solutions).

The baseline definition for motion correction at any time step and for segmentation at time step zero was followed by the segmentation of an organ VOI and the definition of a circular region of interest (ROI) in the aorta for vascular identification. The mean tissue timeattenuation curve was derived automatically and based on these definitions and data the color-coded parameter maps were established and confirmed.

Two radiologists with at least 5 years of experience in interpreting abdominal images each (P.M. and F.F.), independently placed polygonal VOIs encompassing the tumor, blinded to the other radiologist's analysis and other patient information. For exact CT VOI placement, the radiologists had access to the same set of conventional CT/MR images as provided for MRI VOI placement. When possible, upstream and downstream pancreatic parenchyma was also segmented by Reader 1 (P.M.). Calcifications and cystic/ necrotic tumor areas without enhancement were excluded from the VOIs. To avoid a potential bias, the time interval between IVIM DWI analysis and CT perfusion analysis was at least 3 months for each radiologist.

Using a deconvolution model the software calculated the following parameters:

$$
\begin{aligned}
& B F(\text { blood flow })\left[\frac{m l}{100 m l * m i n}\right] \\
& P E M(\text { permeability })\left[\frac{m l}{100 m l * m i n} .\right] \\
& B V(\text { blood volume })\left[\frac{m l}{100 m l}\right]
\end{aligned}
$$

The dose-length-products (DLPs) were calculated from the volume CT dose index $\left(\mathrm{CTDI}_{\mathrm{vol}}\right)$ - values and scan lengths:

$$
D L P=C T D I_{v o l} * s c a n \text { length }
$$

For calculation of the effective dose $\left(D_{\text {eff }}\right)$, the DLPs were multiplied with the corresponding conversion factor for abdominal CT-examinations [25]:

$$
D_{\text {eff }}=\frac{0.015 m S v}{m G y * c m} * D L P
$$

Histology and immunohistochemistry for the assessment of the MVD

In resection specimens, the diagnosis of PDAC was established according to the criteria recommended by the World Health Organization (WHO) and pathological staining was provided using the Union internationale contre le cancer (UICC) criteria. Histopathological 


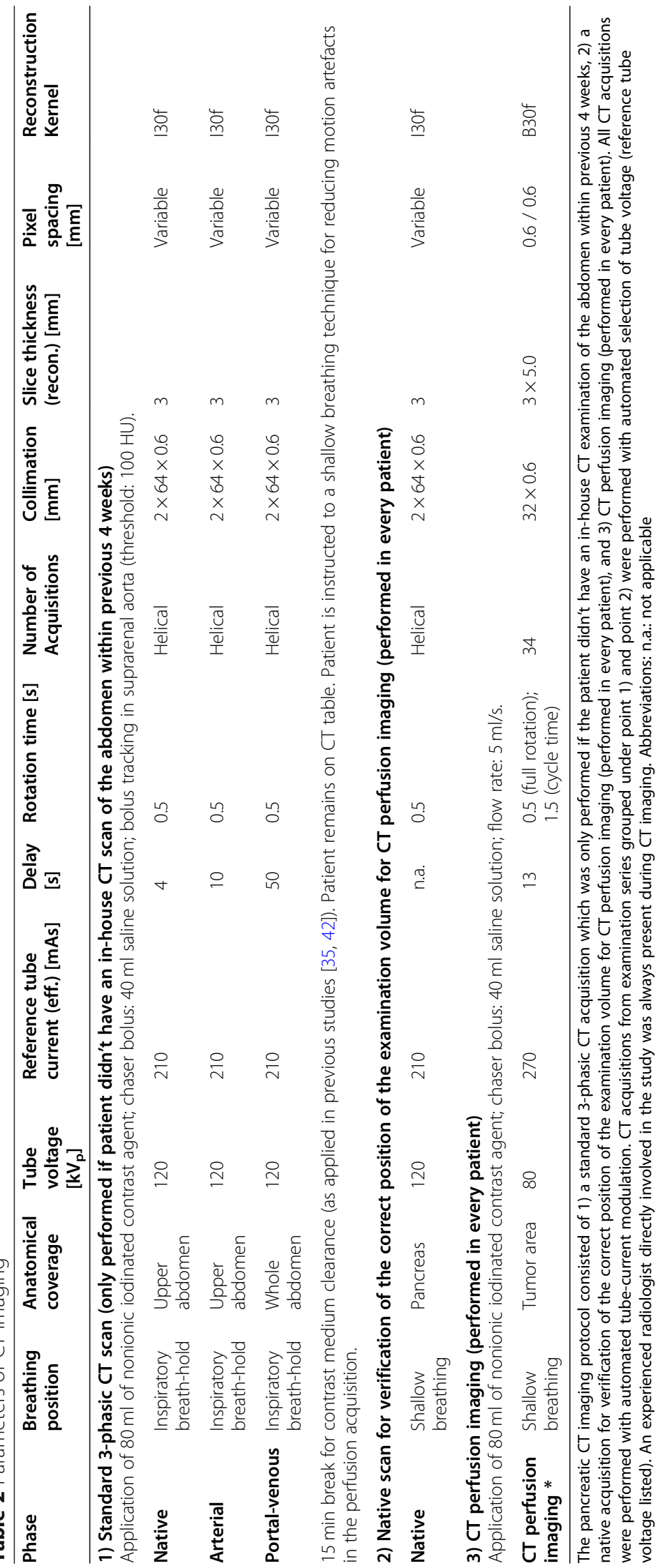


grading was based on combined assessment of growth pattern, mucin content, and mitoses. When heterogeneity (i.e. variation in the degree of differentiation) was seen, the highest grade was assigned.

TNM (tumor, node, metastasis) stages according to the 8th Edition of the UICC Manual and Grading (G) of the 15 resected tumors were as follows: T1 in 1 patient, T2 in 10 patients, T3 in 4 patients, N0 in 3 patients, N1 in 4 patients, $\mathrm{N} 2$ in 8 patients, $\mathrm{M} 0 / \mathrm{x}$ in 14 patients, $\mathrm{M} 1$ in 1 patient. The histopathological grading was G2 in 8 patients, and G3 in 7 patients. Pathological tumor size in these 15 patients ranged from $1.8 \mathrm{~cm}$ to $6.1 \mathrm{~cm}$ (mean value: $3.35 \mathrm{~cm} \pm 1.19 \mathrm{~cm}$ ).

Because of the known tumor heterogeneity [3], tissue selection for tissue-based analysis was performed as previously described. In 10 out of 15 patients who underwent resection for PDAC, representative whole tumor slides from formalin-fixed paraffin-embedded tissue were immunostained with a CD34-specific antibody (1: 25, M7165, Dako), as previously described [19]. In 4 patients, tissue slides of non-neoplastic pancreatic tissue were also immunostained with the CD34-specific antibody.

To generate digital slide images, tissue slides were scanned at 20x magnification using an Aperio slide scanner (Leica Biosystems Aperio). In 10 patients, a mean coherent tumor area of $45 \mathrm{~mm}^{2}$ per tumor, and in $4 \mathrm{pa}-$ tients, representative non-neoplastic pancreatic tissue were then analyzed using the Aperio Microvessel Analysis software (Leica Biosystems Aperio) [26], as previously described [19]. Plausibility was confirmed by pathologists (blinded to clinical information). MVA was calculated as the proportion of the sum of all vessel areas to the total analyzed area, MVD was calculated as mean vessel count per $\mathrm{mm}^{2}$.

\section{Statistical analysis}

Statistical data analysis was performed using MedCalc version 19.2.1 (MedCalc Software Ltd., Ostend, Belgium). Spearman rank correlation coefficients between IVIM-derived parameters, CT perfusion- derived parameters, and MVD/ MVA in tumors were calculated. As proposed by Campbell and Swinscow [27], Spearman correlation was interpreted as very weak $(0.00-0.19)$, weak $(0.20-0.39)$, moderate $(0.40-0.59)$, strong $(0.60-$ $0.79)$, or very strong $(0.80-1.00)$. For comparing correlation coefficients, we used the test recommended by Meng et al., Steiger's Z [28]. For a two-tailed test, Zscores greater than 1.96 or smaller than -1.96 are considered statistically significant. Regression analysis was applied between $f$ and BF, between $f$ and MVD, as well as between BF and MVD, using linear regression models. Mann-Whitney U test was used for comparison of independent continuous variables while Wilcoxon test was used for comparison of dependent continuous variables. Inter-reader reliability was assessed by using the Intraclass Correlation Coefficient (ICC) with 95\% confidence intervals $(\mathrm{CI})$ and applying a 2-way ICC with random raters' assumption reproducibility. As proposed by Song et al. [29], ICC values were interpreted as poor $(0.00-$ $0.20)$, fair $(0.21-0.40)$, moderate $(0.41-0.60)$, good (0.61-0.80), or excellent (0.81-1.00). Receiver operating characteristic (ROC) curves were employed to analyze the diagnostic performance of DWI IVIM and CT perfusion parameters in distinguishing tumors from upstream parenchyma. Due to the small sample size of patients with downstream parenchyma $(n=5)$, ROC curve analysis was not performed for distinguishing tumors from downstream parenchyma. The AUCs with 95\% confidence intervals (CIs) were computed. Sensitivities and specificities of the ROC curves were calculated, and the optimal cut-off values were determined. The DeLong method [30] was used for comparison of areas under the curves (AUCs). As proposed by Mandrekar [31], AUC values were interpreted as acceptable (0.70-0.79), excellent (0.80-0.89), and outstanding (0.90-1.00), while an AUC of 0.5 suggests no discriminatory ability. Significance level was set at 0.05 .

\section{Results \\ DWI IVIM parameters}

Mean tumor perfusion fractions $f_{\text {tumor }}$ for both radiologists ranged from 7.1 to $22.4 \%$ (median: $10.1 \%$; interquartile range [IQR]: 8.9 to $16.6 \%$ ), mean diffusion coefficients $D_{\text {tumor }}$ ranged from $1.0 * 10^{-3} \mathrm{~mm}^{2} / \mathrm{s}$ to 2.0 $* 10^{-3} \mathrm{~mm}^{2} / \mathrm{s}$ (median: $1.2 \times 10^{-3}$; IQR: 1.2 to $1.4 \times 10^{-3}$ $\mathrm{mm}^{2} / \mathrm{sec}$ ), and mean pseudodiffusion coefficients $\mathrm{D}^{*}$ tumor ranged from $6.2 \times 10^{-3} \mathrm{~mm}^{2} / \mathrm{s}$ to $148.5 \times 10^{-3} \mathrm{~mm}^{2} / \mathrm{sec}$ (median: $17.4 \times 10^{-3}$; IQR: 11.4 to $131.9 \times 10^{-3} \mathrm{~mm}^{2} / \mathrm{s}$ ).

Median DWI IVIM parameters for downstream parenchyma for reader 1 (P.M.) were: $22.5 \%$ for $f_{\text {downstream }}$ (IQR: 20.2 to $25.3 \%$ ), $1.7 * 10^{-3} \mathrm{~mm}^{2} / \mathrm{s}$ for $D_{\text {downstream }}$ (IQR: 1.3 to $1.7 * 10^{-3} \mathrm{~mm}^{2} / \mathrm{s}$ ), and $26.3 \times 10^{-3} \mathrm{~mm}^{2} / \mathrm{s}$ for $\mathrm{D}^{*}$ downstream (IQR: 13.7 to $68.1 \times 10^{-3} \mathrm{~mm}^{2} / \mathrm{s}$ ). Median DWI IVIM parameters for upstream parenchyma for reader 1 (P.M.) were: $21.1 \%$ for $f_{\text {upstream (IQR: } 17.6 \text { to }}$ 24.0\%), $1.5 * 10^{-3} \mathrm{~mm}^{2} / \mathrm{s}$ for $\mathrm{D}_{\text {upstream }}$ (IQR: 1.4 to $1.7 *$ $10^{-3} \mathrm{~mm}^{2} / \mathrm{s}$ ), and $21.9 \times 10^{-3} \mathrm{~mm}^{2} / \mathrm{s}$ for $\mathrm{D}^{*}$ upstream (IQR: 11.8 to $34.9 \times 10^{-3} \mathrm{~mm}^{2} / \mathrm{s}$ ). DWI IVIM parameters of tumors, downstream parenchyma, and upstream parenchyma are depicted in Supplementary Figure 1 A-C).

\section{CT perfusion parameters and radiation exposure}

Mean tumor perfusion values $\left(\mathrm{BF}_{\text {tumor }}\right)$ for both radiologists ranged from $14.0 \mathrm{ml} / 100 \mathrm{ml} / \mathrm{min}$ to $98.9 \mathrm{ml} / 100 \mathrm{ml} /$ min (median: $38.9 \mathrm{ml} / 100 \mathrm{ml} / \mathrm{min}$; IQR: 29.0 to $66.2 \mathrm{ml} /$ $100 \mathrm{ml} / \mathrm{min})$. Mean tumor blood volume values $\left(\mathrm{BV}_{\mathrm{tu}}\right.$ mor) ranged from $0.9 \mathrm{ml} / 100 \mathrm{ml}$ to $11.4 \mathrm{ml} / 100 \mathrm{ml}$ 
(median: $2.4 \mathrm{ml} / 100 \mathrm{ml}$; IQR: 1.9 to $4.6 \mathrm{ml} / 100 \mathrm{ml}$ ). Mean tumor permeability values $\left(\mathrm{PEM}_{\text {tumor }}\right)$ ranged from $6.7 \mathrm{ml} / 100 \mathrm{ml} / \mathrm{min}$ to $58.0 \mathrm{ml} / 100 \mathrm{ml} / \mathrm{min}$ (median $17.8 \mathrm{ml} / 100 \mathrm{ml} / \mathrm{min}$; IQR: 11.0 to $28.3 \mathrm{ml} / 100 \mathrm{ml} / \mathrm{min}$ ).

Median CT perfusion parameters for downstream parenchyma for reader 1 (P.M.) were: $141.8 \mathrm{ml} / 100 \mathrm{ml} / \mathrm{min}$ for $\mathrm{BF}_{\text {downstream }}$ (IQR: 131.2 to $173.0 \mathrm{ml} / 100 \mathrm{ml} / \mathrm{min}$ ), $9.9 \mathrm{ml} / 100 \mathrm{ml}$ for $\mathrm{BV}_{\text {downstream }}$ (IQR: 8.7 to $13.3 \mathrm{ml} / 100$ $\mathrm{ml}$ ), and $60.4 \mathrm{ml} / 100 \mathrm{ml} / \mathrm{min}$ for $\mathrm{PEM}_{\text {downstream }}$ (IQR: 53.5 to $67.4 \mathrm{ml} / 100 \mathrm{ml} / \mathrm{min}$ ). Median CT perfusion parameters for upstream parenchyma for reader 1 (P.M.) were: 117.0 for $\mathrm{BF}_{\text {upstream }}$ (IQR: 82.1 to $154.0 \mathrm{ml} / 100 \mathrm{ml}$ / $\min$ ), $8.5 \mathrm{ml} / 100 \mathrm{ml}$ for $\mathrm{BV}_{\text {upstream }}$ (IQR: 5.7 to $14.3 \mathrm{ml} /$ $100 \mathrm{ml}$ ), and $51.4 \mathrm{ml} / 100 \mathrm{ml} / \mathrm{min}$ for $\mathrm{PEM}_{\text {upstream }}$ (IQR: 40.4 to $70.5 \mathrm{ml} / 100 \mathrm{ml} / \mathrm{min}$ ). CT perfusion parameters of tumors, downstream parenchyma, and upstream parenchyma are depicted in Supplementary Figure 1 D-F).

Median DLPs and $D_{\text {eff }}$ were $510.0 \mathrm{mGy} \mathrm{cm} / 7.7 \mathrm{mSv}$ for the standard three-phasic abdominal CT scans $(n=$ 16), $116.0 \mathrm{mGy} \mathrm{cm} / 1.7 \mathrm{mSv}$ for the single native CT acquisitions, and $243.9 \mathrm{mGy} \mathrm{cm} / 3.7 \mathrm{mSv}$ for CT perfusion imaging. There were no adverse reactions to contrast media.

\section{Inter-reader reliability}

Agreement between reader 1 (P.M.) and reader 2 (F.F.) was excellent for $f_{\text {tumor }}$ (ICC $=0.8545,95 \%$ confidence interval (CI): 0.6669 to 0.9409 ), $\mathrm{BF}_{\text {tumor }}$ ( $\mathrm{ICC}=0.8317$, 95\% CI: 0.6164 to 0.9315$), \mathrm{BV}_{\text {tumor }}$ (ICC $=0.9338,95 \%$ CI: 0.8389 to 0.9738$), \mathrm{PEM}_{\text {tumor }}(\mathrm{ICC}=0.9303,95 \% \mathrm{CI}$ : 0.8303 to 0.9725 ), and good for $\mathrm{D}_{\text {tumor }}$ (ICC $=0.7406$, 95\% CI: 0.4491 to 0.8907$)$, as well as $\mathrm{D}^{*}$ tumor $(\mathrm{ICC}=$ $0.7519,95 \%$ CI: 0.4717 to 0.8956 ).

\section{Histopathological parameters}

In the 10 patients in whom representative tumor tissue slides had been immunostained, $\mathrm{MVD}_{\text {tumor }}$ ranged from 21.9/ $\mathrm{mm}^{2}$ to $103.0 / \mathrm{mm}^{2}$ (median: $33.2 / \mathrm{mm}^{2}$; IQR: 25.3 to $61.8 / \mathrm{mm}^{2}$, and $\mathrm{MVA}_{\text {tumor }}$ ranged from 0.007 to 0.045 (median: 0.014; IQR: 0.011 to 0.029).

\section{Comparative data analysis: DWI IVIM and CT perfusion parameters in tumors versus downstream and upstream parenchyma}

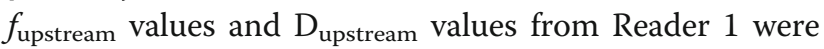
significantly higher than $f_{\text {tumor }}$ values and $D_{\text {tumor }}$ values $(p \leq 0.0010)$. $f_{\text {downstream values }}$ were non-significantly higher than $f_{\text {tumor }}$ values $(p=0.0625)$. $\mathrm{D}_{\text {downstream }}$ did not differ significantly from $\mathrm{D}_{\text {tumor }}(p=0.6250)$ and $\mathrm{D}^{*}$ values did not differ significantly between tumors, downstream, and upstream parenchyma $(p \geq 0.6250)$. BF, BV, and PEM values were significantly lower in tumors than in upstream parenchyma $(p \leq 0.0003)$ and non- significantly lower in tumors than in downstream parenchyma $(p=0.0625)$.

Receiver operating characteristic (ROC) curves (with 95\% CI) of DWI IVIM and CT perfusion parameters from Reader 1 for distinguishing tumors from upstream parenchyma are presented in Supplementary Figure 2. The diagnostic accuracies of BF and BV were outstanding $(\mathrm{AUC}=0.937 ; 95 \% \mathrm{CI}: 0.797$ to 0.991 ; and $\mathrm{AUC}=$ 0.902; 95\% CI: 0.750 to 0.977$)$. PEM and $f$ showed excellent diagnostic accuracy (AUC $=0.888 ; 95 \% \mathrm{CI}$ : 0.732 to 0.970 ; $\mathrm{AUC}=0.874 ; 95 \% \mathrm{CI}: 0.715$ to 0.962 ), while D showed acceptable diagnostic accuracy (AUC $=0.737$; 95\% CI: 0.558 to 0.872 ). D* had the lowest AUC value (AUC $=0.514 ; 95 \% \mathrm{CI}: 0.337$ to 0.688 ). Differences in AUC values between $f$ and BF/BV/PEM were not statistically significant $(p \geq 0.1847)$. Diagnostic accuracy of $\mathrm{D}^{*}$ was significantly lower than diagnostic accuracy of $f / \mathrm{BF} /$ BV/PEM $(p \leq 0.0056)$. The cut-off values with the highest Youden's indices were $\leq 10.7 \%$ for $f$, $\leq 78.2 \mathrm{ml} / 100$ $\mathrm{ml} / \mathrm{min}$ for $\mathrm{BF}, \leq 3.8 \mathrm{ml} / 100 \mathrm{ml}$ for $\mathrm{BV}$, and $\leq 36.6 \mathrm{ml} /$ $100 \mathrm{ml} / \mathrm{min}$ for PEM with corresponding sensitivities of $63.2,89.5,68.4$, and $84.2 \%$ as well as specificities of $100.0,86.7,100.0$, and $93.3 \%$.

\section{Comparative data analysis: DWI IVIM versus CT perfusion versus histological parameters}

Spearman rank correlation coefficients a) between $f_{\text {tumor }}$ and $\mathrm{BF}_{\text {tumor }} / \mathrm{BV}_{\text {tumor, }}$ as well as b) between $\mathrm{MVD}_{\text {tumor }} /$ $\mathrm{MVA}_{\text {tumor }}$ and $f_{\text {tumor }} / \mathrm{BF}_{\text {tumor }} / \mathrm{BV}_{\text {tumor }}$ are listed in Table 3. Spearman rank correlation coefficients between all tumor DWI IVIM-parameters, CT perfusion parameters and histological microvessel parameters are summarized in Supplementary Table 1.

There were significant positive strong Spearman rank correlation coefficients between mean $f_{\text {tumor }}$ for both readers and mean $\mathrm{BF}_{\text {tumor }} / \mathrm{BV}_{\text {tumor }}(\rho \geq 0.668, p \leq$ $0.0018)$ in all patients $(n=19$, Table 3$)$. Moreover, there were significant positive strong to very strong Spearman rank correlation coefficients between mean $\mathrm{MVD}_{\text {tumor }} /$

Table 3 Spearman rank correlation coefficients

\begin{tabular}{|c|c|c|c|}
\hline \multicolumn{4}{|c|}{$\begin{array}{l}\text { Spearman correlations between mean } f_{\text {tumor }} \text { from DWI IVIM and } \\
\text { mean CT perfusion parameters }(n=19)\end{array}$} \\
\hline & $\mathrm{BF}_{\text {tumor }}$ & \multicolumn{2}{|l|}{$\mathrm{BV}_{\text {tumor }}$} \\
\hline$f_{\text {tumor }}$ & $0.668 *$ & \multicolumn{2}{|l|}{$0.672 *$} \\
\hline \multicolumn{4}{|c|}{$\begin{array}{l}\text { Spearman correlations between histological microvessel } \\
\text { parameters, mean } f_{\text {tumor }} \text { from DWI IVIM and mean CT perfusion } \\
\text { parameters }(n=10)\end{array}$} \\
\hline & $f_{\text {tumor }}$ & $\mathrm{BF}_{\text {tumor }}$ & $\mathrm{BV}_{\text {tumor }}$ \\
\hline $\mathrm{MVD}_{\text {tumor }}$ & $0.770 *$ & $0.697 *$ & $0.661 *$ \\
\hline $\mathrm{MVA}_{\text {tumor }}$ & $0.818 *$ & $0.709 *$ & $0.661 *$ \\
\hline
\end{tabular}

Correlation coefficients that are significantly different from zero $(p<0.05)$ are marked with *. Abbreviations: BF: blood flow, BV: blood volume, $f$ : perfusion fraction, MVA: microvessel area, MVD: microvessel density 

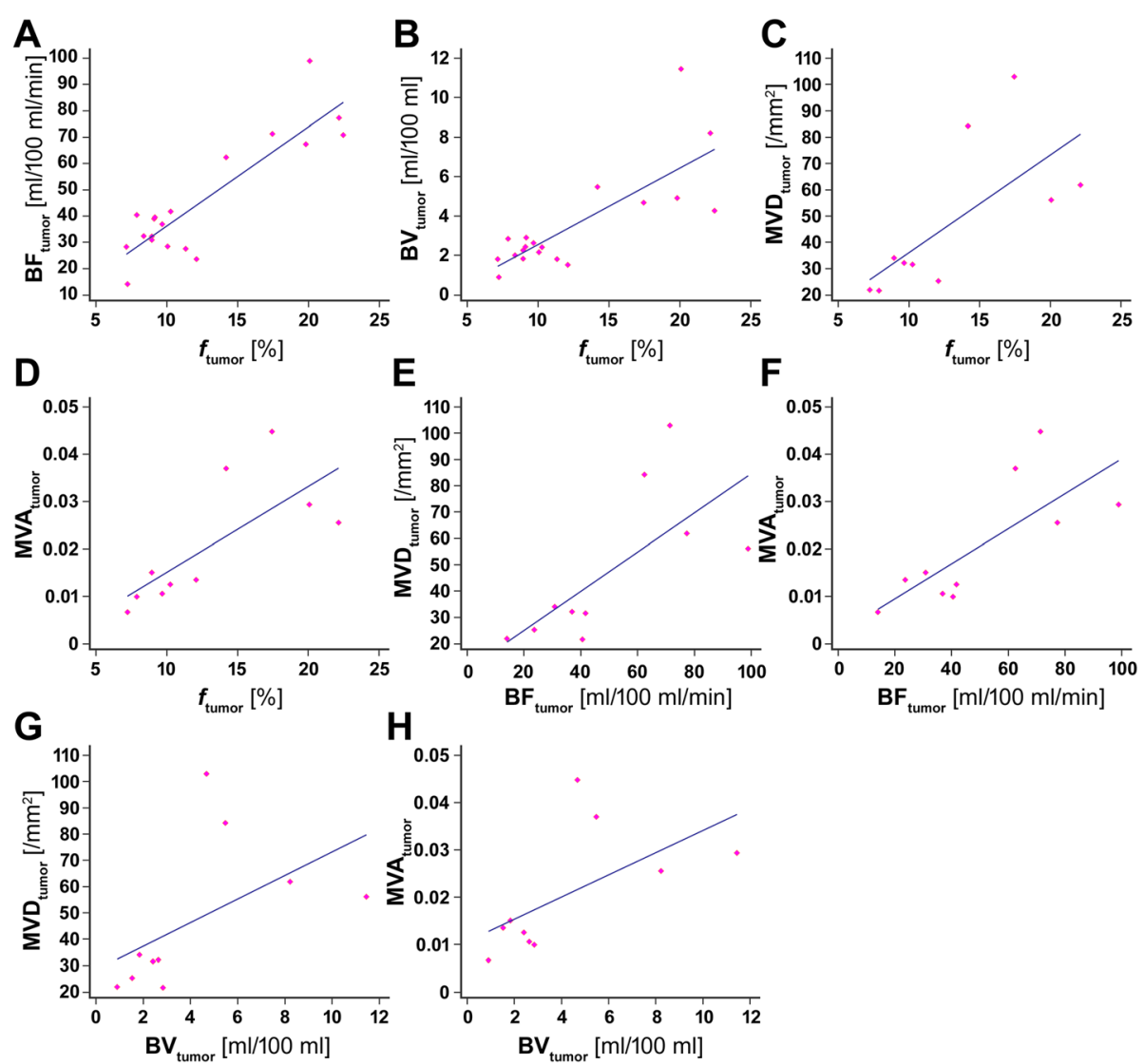

Fig. 1 Scatter plots with the results of the regression analysis. A) Scatter plot of the perfusion fraction $f_{\text {tumor }} v$ s. BF tumor. Linear regression model: $B F_{\text {tumor }}\left[\frac{\mathrm{m} /}{100 \mathrm{~m} / * \mathrm{~min}}\right]=3.772 \frac{\mathrm{ml}}{100 \mathrm{~m} / * \min * \%} * f_{\text {tumor }}[\%]-1.471 \frac{\mathrm{ml}}{100 \mathrm{~m} / * \mathrm{~min}}$. Goodness of fit: $R^{2}=0.774$. B) Scatter plot of the perfusion fraction $f_{\text {tumor }}$ vs. $B V_{\text {tumor }}$. Linear regression model: $B V_{\text {tumor }}\left[\frac{\mathrm{ml}}{100 \mathrm{~m}]}\right]=0.388 \frac{\mathrm{ml}}{100 \mathrm{~m} / * \%} * f_{\text {tumor }}[\%]-1.327 \frac{\mathrm{ml}}{100 \mathrm{~m} /}$ Goodness of fit: $R^{2}=0.608$. C) Scatter plot of the perfusion fraction $f_{\text {tumor }} V S$. $M V D_{\text {tumor. }}$. Linear regression model: $M V D_{\text {tumor }}\left[\frac{1}{\mathrm{~mm}^{2}}\right]=3.721 \frac{1}{\mathrm{~mm}^{2} * \%} * f_{\text {tumor }}[\%]-1.144 \frac{1}{\mathrm{~mm}^{2}}$. Goodness of fit: $R^{2}=0.476$. D) Scatter plot of the perfusion fraction $f_{\text {tumor }} v s$. MVA tumor. Linear regression model: $M V A_{\text {tumor }}=0.00181 \frac{1}{\sigma} * f_{\text {tumor }}[\%]-0.00306$. Goodness of fit: $R^{2}=0.548$. E) Scatter plot of $B F_{\text {tumor }} V S . M V D_{\text {tumor }}$. Linear regression model: $M V D_{\text {tumor }}\left[\frac{1}{\mathrm{~mm}^{2}}\right]=0.745 \frac{100 \mathrm{~m} / * \min }{\mathrm{mm}^{2} * \mathrm{ml}} * B F_{\text {tumor }}\left[\frac{\mathrm{ml}}{100 \mathrm{~m} / * \mathrm{~min}}\right]+10.125 \frac{1}{\mathrm{~mm} \mathrm{~m}^{2}}$. Goodness of fit: $R^{2}=0.490$. F) Scatter plot of $B F_{\text {tumor }}$ VS. MVA tumor Linear regression model: $M V A_{\text {tumor }}=0.00037 \frac{100 \mathrm{~m} / * \mathrm{~min}}{\mathrm{~m} / \mathrm{m}} * B F_{\text {tumor }}\left[\frac{\mathrm{ml}}{100 \mathrm{~m} / * \mathrm{~min}}\right]+0.002$ 09. Goodness of fit: $R^{2}=0.578$. G) Scatter plot of $B V_{\text {tumor }}$ VS. $M V D_{\text {tumor. }}$ Linear regression model: $M V D_{\text {tumor }}\left[\frac{1}{m^{2}}\right]=4.489 \frac{100 \mathrm{ml}}{\mathrm{mm}^{2} * \mathrm{ml} /} * B V_{\text {tumor }}\left[\frac{\mathrm{ml}}{100 \mathrm{~m}}\right]+28.3$ $46 \frac{1}{\mathrm{~mm}^{2}}$. Goodness of fit: $R^{2}=0.281$. H) Scatter plot of $B V_{\text {tumor }}$ VS. MVA tumor.. Linear regression model: $M V A_{\text {tumor }}=0.00235 \frac{100 \mathrm{ml}}{\mathrm{ml}} * B V_{\text {tumor }}\left[\frac{\mathrm{ml}}{100 \mathrm{~m}]}\right]+0.01$ 06. Goodness of fit: $R^{2}=0.372$

$\mathrm{MVA}_{\text {tumor }}$ for both readers and mean $f_{\text {tumor }} / \mathrm{BF}_{\text {tumor }} /$ $\mathrm{BV}_{\text {tumor }}$ in the 10 patients in whom histological microvessel analysis was performed $(\rho \geq 0.661, p \leq 0.0376$, Table 3).

There were no significant Spearman rank correlations between mean $D_{\text {tumor }} / \mathrm{D}^{*}$ tumor for both readers and mean $\mathrm{BF}_{\text {tumor }} / \mathrm{BV}_{\text {tumor }}$ in all patients $(|\rho| \leq 0.392, p \geq$ 0.0972) or between $\mathrm{MVD}_{\text {tumor }} / \mathrm{MVA}_{\text {tumor }}$ and mean $\mathrm{D}_{\text {tu- }}$ mor $/ \mathrm{D}^{*}$ tumor $/ \mathrm{PEM}_{\text {tumor }}$ in the 10 patients in whom histological microvessel analysis was performed ( $|\rho| \leq 0.527, p \geq 0.1173$ ). Also, the product $f_{\text {tumor }} \mathrm{x}$ $\mathrm{D}^{*}$ tumor, which supposedly reflects capillary blood flow [32], was not significantly correlated to $\mathrm{BF}_{\text {tumor }} / \mathrm{BV}_{\text {tu- }}$ mor $/ M D_{\text {tumor }} / \operatorname{MVA}_{\text {tumor }}(|\rho| \leq 0.200, p \geq 0.5617)$.
Correlation coefficients between mean $\mathrm{MVD}_{\text {tumor }} /$ $\mathrm{MVA}_{\text {tumor }}$ for both readers and mean $f$ were not significantly different from correlation coefficients between mean $\mathrm{MVD}_{\text {tumor }} / \mathrm{MVA}_{\text {tumor }}$ and mean $\mathrm{BF}_{\text {tumor }}(p \geq$ 0.4001, $\mid \mathrm{Z}$-score $\mid \leq 0.840)$. Also, correlations between mean $\mathrm{MVD}_{\text {tumor }} / \mathrm{MVA}_{\text {tumor }}$ and mean $\mathrm{BF}$ for both readers were not significantly different from correlations between mean $\mathrm{MVD}_{\text {tumor }} / \mathrm{MVA}_{\text {tumor }}$ and mean $\mathrm{BV}_{\text {tumor }}$ $(p \geq 0.5652, \mid Z$-score $\mid \leq 0.575)$.

$\mathrm{D}_{\text {tumor }}, \mathrm{D}_{\text {tumor }}, f_{\text {tumor }}, \mathrm{BF}_{\text {tumor }}$, and $\mathrm{BV}_{\text {tumor }}$ values did not differ significantly between moderately differentiated (G2) and poorly differentiated tumors (G3, $p \geq 0.4495)$.

MVA and MVA values were higher in non-neoplastic parenchyma than in tumors for all 4 patients in whom 
histological microvessel parameters were analyzed both in tumors and non-neoplastic parenchyma ( $p=0.1250$, Supplementary Figure 3).

Scatter plots with the results of the regression analyses are shown in Fig. 1. The correlations between the displayed parameters $f_{\text {tumor }}, \mathrm{BF}_{\text {tumor }}, \mathrm{BV}_{\text {tumor }}, \mathrm{MVD}_{\text {tumor }}$, and $\mathrm{MVA}_{\text {tumor }}$ are well visible.

Example pictures of PDAC patients with low and high perfusion/microvasculature are shown in Figs. 2 and 3.

\section{Discussion}

The presented study evaluates tumor tissue perfusion as possible imaging biomarker in PDAC. In PDAC patients, tumor tissue perfusion was quantified by means of IVIM DW MRI as well as CT perfusion, and correlated with histologically determined $\mathrm{MVD}_{\text {tumor }} / \mathrm{MVA}_{\text {tumor }}$.

We used the deconvolution model for CT perfusion analysis since it can tolerate greater image noise than compartment models and was reported to be well suited for measuring lower levels of perfusion [33], as expected in PDAC. The deconvolution-based $\mathrm{BF}_{\text {tumor }}$ values obtained in our current study were similar to previously reported deconvolution-based $\mathrm{BF}_{\text {tumor }}$ values in PDAC
[34], but considerably higher than previously reported $\mathrm{BF}_{\text {tumor }}$ values based on the maximum-slope approach in PDAC $[34,35]$. This difference between $\mathrm{BF}_{\text {tumor }}$ values obtained from the different models might be attributable to differences in the two mathematical calculation methods [34]. Mean $\mathrm{BV}_{\text {tumor }}$ and $\mathrm{PEM}_{\text {tumor }}$ values were within the same range as those reported by Schneeweiß et al. [34]. Also, mean values of the DWI IVIM parameters, as well as the histological microvessel parameters were within the same range as in a previous study by Klauß et al. [19].

The results of the current study confirm significant positive rank correlations between the IVIM-derived perfusion fraction $f_{\text {tumor }}$ and $\mathrm{MVD}_{\text {tumor }} / \mathrm{MVA}_{\text {tumor }}$ in PDAC. Similarly to a study by Klauß et al. there was no significant rank correlation between $\mathrm{D}^{*}$ tumor and $\mathrm{MVD}_{\text {tu- }}$ mor or $\mathrm{MVA}_{\text {tumor }}$, although $\mathrm{D}^{*}$ is supposed to be a flowrelated parameter [19]. A possible explanation for this observation could be linked to a study by Lemke et al. where the estimate of the pseudo-diffusion coefficient $D^{*}$ was found to be much less stable than the estimate of the perfusion fraction $f[36]$. As expected, the diffusion coefficient $\mathrm{D}_{\text {tumor }}$ did not significantly correlate
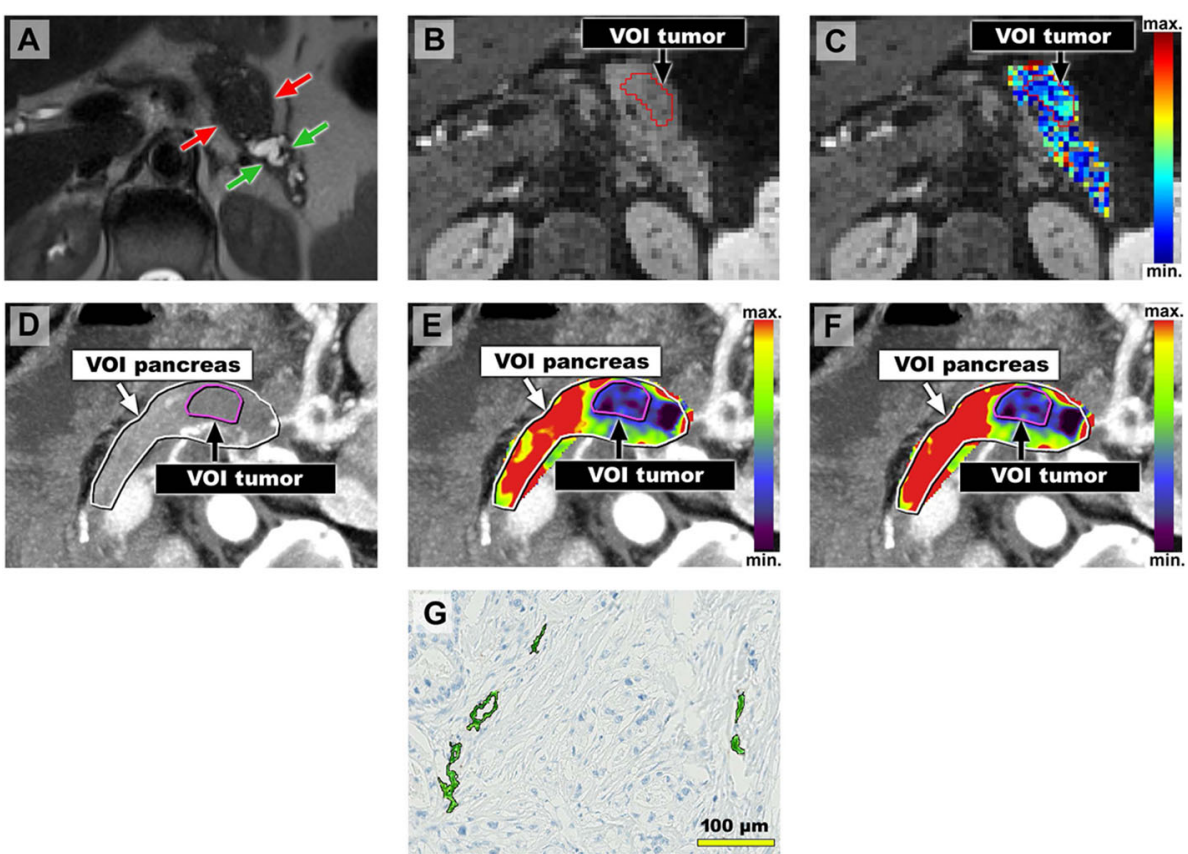

Fig. 2 Image examples of a patient with comparatively low tumor vascularity. 64 years old female patient with PDAC of the pancreatic corpus/ tail. a-c) Axial MR images with the patient in supine position. a Axial T2-HASTE MR image shows upstream dilatation of the main pancreatic duct and concomitant parenchymal atrophy (green arrows) due to an obstructing tumor in the pancreatic corpus/ tail (red arrows). $\mathbf{b}$ Diffusion-weighted MR image $\left(b=300 \mathrm{~s} / \mathrm{mm}^{2}\right)$ with a VOI encompassing the tumor (VOI tumor). c Diffusion-weighted MR imaging with

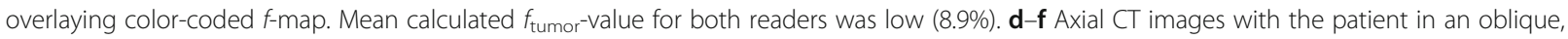
$30^{\circ}$, right-sided down position. $\mathbf{d}$ Temporal maximum intensity projection (MIP) CT images of the perfusion sequence with VOls encompassing the pancreas (VOI pancreas) and the tumor (VOI tumor). e-f Temporal MIP CT images with color-coded parameter maps for blood flow (BF tumor, e) and blood volume $\left(\mathrm{BV}_{\text {tumor, }} \mathbf{f}\right)$ derived from perfusion-sequence. Mean $\mathrm{BF}_{\text {tumor }}$ and $\mathrm{BV}_{\text {tumor }}$ were $10 \mathrm{w}(30.9 \mathrm{ml} / 100 \mathrm{ml} / \mathrm{min}$ and $1.8 \mathrm{ml} / 100 \mathrm{ml})$. g) Representative cutout of corresponding immunostained tissue slide (CD34) after semi-automated segmentation of microvessels shows low $M V D_{\text {tumor }} \cdot \mathrm{MVD}_{\text {tumor }}$ in total analysis area was $34.1 / \mathrm{mm}^{2}$ 

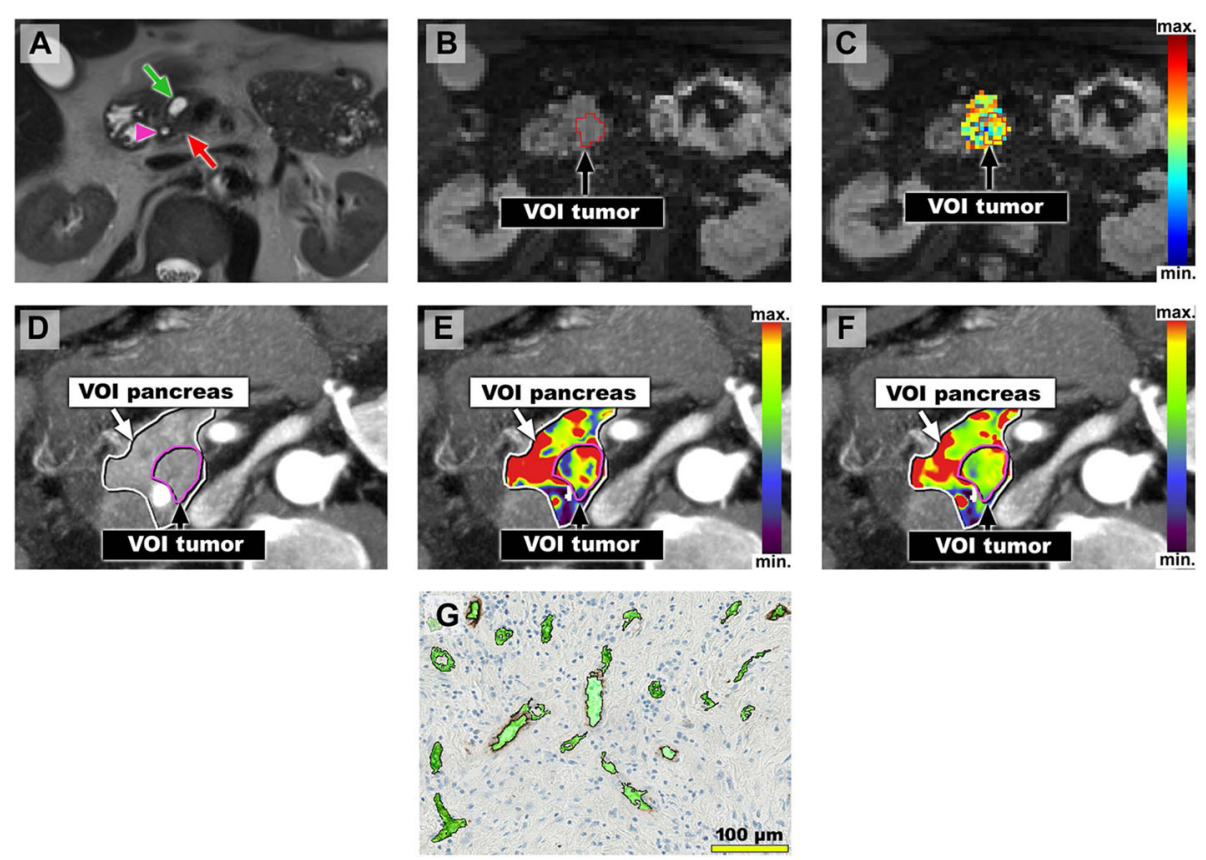

Fig. 3 Image examples of a patient with comparatively high tumor vascularity. 58 years old male patient with PDAC of the pancreatic head. a-c Axial MR images with the patient in supine position. a Axial T2-HASTE MR image shows upstream dilatation of the main pancreatic duct (green arrow) due to an obstructing tumor in the pancreatic head (red arrow). Stent in the distal common bile duct which is not dilated (pink arrowhead). b Diffusion-weighted MR image $\left(b=300 \mathrm{~s} / \mathrm{mm}^{2}\right.$ ) caudad to the T2-HASTE image with a VOI encompassing the tumor (VOI tumor). $\mathbf{c}$ Diffusion-weighted MR imaging with overlaying color-coded $f$-map. Mean calculated $f_{\text {tumor }}$-value for both readers was high (22.1\%). $\mathbf{d}$-f $A$ Axial $C T$ images with the patient in an oblique, $30^{\circ}$, right-sided down position. D) Temporal maximum intensity projection (MIP) CT images of the perfusion sequence with VOls encompassing the pancreas (VOI pancreas) and the tumor (VOI tumor). e-f Temporal MIP CT images with colorcoded parameter maps for blood flow $\left(\mathrm{BF}_{\text {tumor, }} \mathbf{e}\right)$ and blood volume ( $\left.\mathrm{BV}_{\text {tumor, }} \mathbf{f}\right)$ derived from perfusion-sequence. Mean $\mathrm{BF}_{\text {tumor }}$ and $\mathrm{BV}_{\text {tumor }}$ were comparatively high $(77.3 \mathrm{ml} / 100 \mathrm{ml} / \mathrm{min}$ and $8.2 \mathrm{ml} / 100 \mathrm{ml})$. g Representative cutout of corresponding immunostained tissue slide (CD34) after semi-automated segmentation of microvessels shows high $\mathrm{MVD}_{\text {tumor. }} \mathrm{MVD}_{\text {tumor }}$ in total analysis area was $61.8 / \mathrm{mm}^{2}$

with histological microvessel parameters in our present study. D represents perfusion-free diffusion [16] and was shown to reflect changes in the microarchitecture of the PDAC stroma [3].

The current study demonstrates that $\mathrm{CT}$ perfusion is a useful tool to evaluate tumor vascularity in PDAC. In the present study, $\mathrm{BF}_{\text {tumor }}$ and $\mathrm{BV}_{\text {tumor }}$ from $\mathrm{CT}$ perfusion similarly reflected $\mathrm{MVD}_{\text {tumor }}$ in PDAC. However, in a study on PNEN, $\mathrm{BF}_{\text {tumor }}$ significantly correlated with $\mathrm{MVD}_{\text {tumor }}$ whereas $\mathrm{BV}_{\text {tumor }}$ did not [18], which is in contrast to a study on colorectal cancer [37]. These discrepancies might be caused by differences in the microstructure of these tumor entities.

Rank correlations between microvessel parameters and $\mathrm{PEM}_{\text {tumor }}$ from CT perfusion were not significant in the current study. This is logical since PEM $\mathrm{PM}_{\text {tumor }}$ reflects features of microvessels like the microanatomy of the basement membrane rather than microvessel count [38]. Likewise, a study on PNEN failed to detect a significant correlation between PEM and MVD [18].

Probably the most important finding of the current study is that the applicability of DW IVIM MRI seems to be comparable to the applicability of CT perfusion for the assessment of tumor tissue perfusion. This finding is relevant for oncological imaging since tumor tissue perfusion can be used as imaging biomarker for treatment assessment [13]. This finding might also explain the excellent performance of both the perfusion fraction $f$ from IVIM and CT perfusion parameters in distinguishing the notoriously hypovascular PDAC [39] from nonneoplastic pancreatic parenchyma in the present and previous studies $[40,41]$. Valuable statements on the applicability of different radiological methods for the assessment of tumor vascularity can be accomplished only by direct comparison of methods and validation with histological microvessel parameters as ground truth. Similar studies should be performed in other solid tumors to further evaluate the interrelations of DW IVIM MRI, CT perfusion, and histological tumor microvascularity.

There are some limitations to our study. First, our patient sample is relatively small, although the time spent and effort per patient were comparatively high. Second, the complete series of tissue slides, to overcome the tumor heterogeneity, for histological and microvessel analysis were only available in 10 out of the 15 patients, 
who underwent surgery with curative intent for PDAC. Strikingly, this number of patients was still sufficient to prove significant correlations between microvessel parameters and $f_{\text {tumor }}$ as well as $\mathrm{BF}_{\text {tumor }}$ and $\mathrm{BV}_{\text {tumor }}$. Third, the complete series of tissue slides was inspected in these 10 patients and representative tissue samples for microvessel analysis were chosen. However, these tissue samples weren't completely congruent to the VOIs of the IVIM and CT perfusion analysis.

\section{Conclusion}

In conclusion, this study shows that $f_{\text {tumor }}$ and $\mathrm{BF}_{\text {tumor }} /$ $\mathrm{BV}_{\text {tumor }}$ similarly reflect microvasculature in PDAC and seem to be comparably applicable for the evaluation of tumor tissue perfusion for tumor characterization.

\section{Supplementary Information}

The online version contains supplementary material available at https://doi. org/10.1186/s40644-021-00382-x.

Additional file 1 Supplementary Figure 1. Line diagrams of DWI IVIM and CT perfusion parameters of tumors, downstream parenchyma, and upstream parenchyma. Line diagrams depicting (A) f-values, (B) D-values, (C) D*-values, D) BF-values, E) BV-values, and F) PEM-values from Reader 1 (P.M.). Each line represents one patient.

Additional file 2 Supplementary Figure 2. ROC curves for differentiation of tumors from upstream parenchyma. ROC-curves for differentiation of tumors from upstream parenchyma using DWI IVIM and CT perfusion parameters from Reader 1. AUC-values were 0.874 (95\% Cl: 0.715 to 0.962$)$ for $f, 0.737$ (95\% Cl: 0.558 to 0.872$)$ for D, $0.514(95 \% \mathrm{Cl}$ : 0.337 to 0.688 ) for $D^{*}, 0.937$ (95\% Cl: 0.797 to 0.991$)$ for BF, 0.902 ( $95 \% \mathrm{Cl}$ : 0.750 to 0.977 ) for BV and 0.888 ( $95 \% \mathrm{Cl}: 0.732$ to 0.970 ) for PEM.

Additional file 3 Supplementary Figure 3. Microvessel analysis in non-neoplastic parenchyma. A) Representative cutout of immunostained non-neoplastic pancreatic tissue (CD34) after semiautomated segmentation of microvessels shows relatively high microvessel density. Segmentation of microvessels was performed using Aperio Microvessel Analysis software, with CD34 positive endothelial cells surrounding a (slit-like) lumen. Dotted CD34 expressions are mast cells, dendritic cells, and activated stroma cells. B) and C) Line diagrams depicting MVD and MVA values in non-neoplastic pancreatic parenchyma and tumors. Each line represents one patient. $M V D_{\text {non-neoplastic }}$ and $M V A_{\text {non-neo- }}$ plastic values were higher than corresponding $\mathrm{MVD}_{\text {tumor }}$ and $M V A_{\text {tumor }}$ values in all 4 patients $(p=0.1250)$.

Additional file 4 Supplementary Table 1. Spearman rank correlation coefficients between all tumor DWI IVIM parameters, CT perfusion parameters, and histological microvessel parameters in tumors.

\section{Abbreviations}

BF: Blood flow; BV: Blood volume; Cl: Confidence interval; CT: Computed tomography; $C \mathrm{CT}_{\mathrm{yol}}$ : Volumetric $\mathrm{CT}$ dose index; D: Diffusion coefficient:

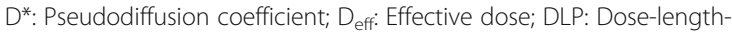
product; DW: Diffusion weighted; DWl: Diffusion weighted imaging; f: perfusion fraction; IQR: Interquartile range; IVIM: Intravoxel Incoherent Motion; MITK: Medical Imaging Interaction Toolkit; MRI: Magnetic resonance imaging; MVA: Microvessel area; MVD: Microvessel density; PDAC: Pancreatic ductal adenocarcinoma; PEM: Permeability values; PNEN: Neuroendocrine neoplasm; SMA: Superior mesenteric artery; UICC: Union Internationale Contre le Cancer; VOI: Volume of interest; WHO: World Health Organization

\section{Acknowledgements}

The results of the study were presented at the European Society of Gastrointestinal and Abdominal Radiology (ESGAR) Annual Meeting on 14th of June 2018 (presentation number SS 8.5, ID 53944).

We thank Natalie Tessendorf for excellent technical support.

The study was supported by the Tissue bank of the National Centre for Tumor Disease, Heidelberg, Germany.

\section{Authors' contributions}

Conceptualization, P.M., F.F., S.S., K.M.H., H.U.K., M.K., and W.S.; establishment of DW-MRI sequences, F.B.L.; establishment of CT perfusion protocol, S.S., W.S.; patient acquisition, P.M., F.F., M.K.; analysis of DW MRI data and CT perfusion data, P.M., F.F.; histopathological evaluation, F.B., M.M.G.; collection of clinical patient data, T.H.; statistical analysis, P.M.; interpretation of data; P.M., F.F., M.K., W.S., L.G.; writing—original draft preparation, P.M.; writing—review and editing, K.M.H., F.B.L., H.U.K., L.G., S.S., and W.S.; visualization, P.M. All authors have read and agreed to the final version of the manuscript.

\section{Funding}

The study was supported financially by the German Research Foundation (DFG) within the projects R01 ("Functional Diffusion-Weighted Imaging for Tissue Analysis") and R02 ("Innovative Imaging of Tissue Perfusion") of the Transregional Collaborative Research Center SFB/TRR 125 "Cognition-guided Surgery". M.M.G. and F.B.L. were also supported by the DFG (GA 18181/2-1, LA 2804/6-1). Open Access funding enabled and organized by Projekt DEAL.

\section{Availability of data and materials}

The datasets generated during and/or analysed during the current study are available from the corresponding author on reasonable request.

\section{Ethics approval and consent to participate}

The study protocol of our prospective study was approved by our institutional review board and informed consent was obtained from the patients before the examination.

\section{Consent for publication}

Not applicable.

\section{Competing interests}

W.S. is a member of the CT Advisory Board of Philips Medical Systems.

\section{Author details}

${ }^{1}$ Clinic for Diagnostic and Interventional Radiology (DIR), Heidelberg University Hospital, Im Neuenheimer Feld 420, 69120 Heidelberg, Germany. ${ }^{2}$ Institute of Pathology, Heidelberg University Hospital, Im Neuenheimer Feld 224, 69120 Heidelberg, Germany. ${ }^{3}$ Institute of Pathology, University Medical Center Mainz, Johannes Gutenberg-University Mainz, Langenbeckstrasse 1, 55131 Mainz, Germany. ${ }^{4}$ Department of General, Visceral, and Transplantation Surgery, Heidelberg University Hospital, Im Neuenheimer Feld 420, 69120 Heidelberg, Germany. ${ }^{5}$ Department of Medical Imaging Computing, German Cancer Research Center, Im Neuenheimer Feld 223, 69120 Heidelberg, Germany. ${ }^{6}$ Department of Medical Physics in Radiology, German Cancer Research Center, Im Neuenheimer Feld 223, 69120 Heidelberg, Germany. ${ }^{7}$ Institute of Radiology, University Hospital Erlangen, Maximiliansplatz 3, 91054 Erlangen, Germany. ${ }^{8}$ Conradia Radiology Munich, Augustenstraße 115, 80798 Munich, Germany.

Received: 29 June 2020 Accepted: 6 January 2021

Published online: 19 January 2021

\section{References}

1. Raimondi S, Maisonneuve P, Lowenfels AB. Epidemiology of pancreatic cancer: an overview. Nat Rev Gastroenterol Hepatol. 2009:6:699-708.

2. Alam MS, Gaida MM, Bergmann F, Lasitschka F, Giese T, Giese NA, et al. Selective inhibition of the p38 alternative activation pathway in infiltrating $T$ cells inhibits pancreatic cancer progression. Nat Med. 2015;21:1337-43.

3. Mayer P, Dinkic C, Jesenofsky R, Klauss M, Schirmacher P, Dapunt U, et al. Changes in the microarchitecture of the pancreatic cancer stroma are linked to neutrophil-dependent reprogramming of stellate cells and reflected by diffusion-weighted magnetic resonance imaging. Theranostics. 2018;8:13-30. 
4. Linnebacher A, Mayer P, Marnet N, Bergmann F, Herpel E, Revia S, et al. Interleukin 21 receptor/ligand interaction is linked to disease progression in pancreatic cancer. Cells. 2019;8:1104.

5. Niedergethmann M, Hildenbrand R, Wostbrock B, Hartel M, Sturm JW, Richter A, et al. High expression of vascular endothelial growth factor predicts early recurrence and poor prognosis after curative resection for ductal adenocarcinoma of the pancreas. Pancreas. 2002;25:122-9.

6. Niedergethmann M, Hildenbrand R, Wolf G, Verbeke CS, Richter A, Post S. Angiogenesis and cathepsin expression are prognostic factors in pancreatic adenocarcinoma after curative resection. Int J Pancreatol Off J Int Assoc Pancreatol. 2000;28:31-9.

7. Fujioka S, Yoshida K, Yanagisawa S, Kawakami M, Aoki T, Yamazaki Y. Angiogenesis in pancreatic carcinoma: thymidine phosphorylase expression in stromal cells and intratumoral microvessel density as independent predictors of overall and relapse-free survival. Cancer. 2001;92:1788-97.

8. Ikeda N, Adachi M, Taki T, Huang C, Hashida H, Takabayashi A, et al. Prognostic significance of angiogenesis in human pancreatic cancer. $\mathrm{Br} J$ Cancer. 1999;79:1553-63.

9. Benckert C, Thelen A, Cramer T, Weichert W, Gaebelein G, Gessner R, et al. Impact of microvessel density on lymph node metastasis and survival after curative resection of pancreatic cancer. Surg Today. 2012;42:169-76.

10. Khan AW, Dhillon AP, Hutchins R, Abraham A, Shah SR, Snooks S, et al. Prognostic significance of intratumoural microvessel density (IMD) in resected pancreatic and ampullary cancers to standard histopathological variables and survival. Eur J Surg Oncol. 2002;28:637-44.

11. Takagi K, Takada T, Amano H. A high peripheral microvessel density count correlates with a poor prognosis in pancreatic cancer. J Gastroenterol. 2005; 40:402-8.

12. van der Zee JA, van Eijck CHJ, Hop WCJ, van Dekken H, Dicheva BM, Seynhaeve ALB, et al. Angiogenesis: a prognostic determinant in pancreatic cancer? Eur J Cancer. 2011;47:2576-84.

13. Miles KA, Lee T-Y, Goh V, Klotz E, Cuenod C, Bisdas S, et al. Current status and guidelines for the assessment of tumour vascular support with dynamic contrast-enhanced computed tomography. Eur Radiol. 2012;22:1430-41.

14. Schmitz-Winnenthal FH, Hohmann N, Niethammer AG, Friedrich T, Lubenau $\mathrm{H}$, Springer $\mathrm{M}$, et al. Anti-angiogenic activity of VXM01, an oral T-cell vaccine against VEGF receptor 2, in patients with advanced pancreatic cancer: a randomized, placebo-controlled, phase 1 trial. Oncoimmunology. 2015;4: e1001217.

15. Fritz F, Skornitzke S, Hackert T, Kauczor HU, Stiller W, Grenacher L, et al. Dual-energy perfusion-CT in recurrent pancreatic cancer - preliminary results. Rofo. 2016;188:559-65.

16. Le Bihan D, Breton E, Lallemand D, Aubin ML, Vignaud J, Laval-Jeantet M. Separation of diffusion and perfusion in intravoxel incoherent motion MR imaging. Radiology. 1988;168:497-505.

17. García-Figueiras R, Goh VJ, Padhani AR, Baleato-González S, Garrido M, León $L$, et al. CT perfusion in oncologic imaging: a useful tool? AJR Am J Roentgenol. 2013;200:8-19.

18. d'Assignies G, Couvelard A, Bahrami S, Vullierme M-P, Hammel P, Hentic O, et al. Pancreatic endocrine tumors: tumor blood flow assessed with perfusion CT reflects angiogenesis and correlates with prognostic factors. Radiology. 2009;250:407-16.

19. Klauß M, Mayer P, Bergmann F, Maier-Hein K, Hase J, Hackert T, et al. Correlation of histological vessel characteristics and diffusion-weighted imaging intravoxel incoherent motion-derived parameters in pancreatic ductal adenocarcinomas and pancreatic neuroendocrine tumors. Investig Radiol. 2015;50:792-7.

20. Yu, Mi Hye, Lee, Jeong-Min, Han, Joon Koo, Choi, Byung Ihn. Perfusion CT in patients with hepatocellular carcinoma: comparison with intravoxel incoherent motion diffusion (IVIM)- diffusion weighted imaging (DWI). [Internet]. Chicago, IL, USA; 2013 [cited 2020 May 15]. Available from: http:// archive.rsna.org/2013/13024811.html

21. Pang Y, Turkbey B, Bernardo M, Kruecker J, Kadoury S, Merino MJ, et al. Intravoxel incoherent motion MR imaging for prostate cancer: an evaluation of perfusion fraction and diffusion coefficient derived from different $b$ -value combinations. Magn Reson Med. 2013;69:553-62.

22. Fritzsche $\mathrm{KH}$, Neher PF, Reicht I, van Bruggen $T$, Goch C, Reisert M, et al. MITK diffusion imaging. Methods Inf Med. 2012;51:441-8.

23. Klaassen R, Gurney-Champion OJ, Engelbrecht MRW, Stoker J, Wilmink JW, Besselink MG, et al. Evaluation of six diffusion-weighted MRI models for assessing effects of neoadjuvant chemoradiation in pancreatic cancer patients. Int J Radiat Oncol Biol Phys. 2018;102:1052-62.

24. Richter GM, Wunsch C, Schneider B, Düx M, Klar E, Seelos R, et al. Hydro-CT in detection and staging of pancreatic carcinoma. Radiologe. 1998;38:27986.

25. ICRP EK, Harrison J, Menzel H-G, Clement CH. ICRP Publication 119: Compendium of dose coefficients based on ICRP Publication 60. Ann ICRP. 2012;41(Suppl 1):1-130.

26. Potts SJ, Lillard K, Johnson T, Voelker F, Valdez R. P26: performance of a novel automated microvessel analysis algorithm across whole slide digital images. Exp Toxicol Pathol. 2009;61:413.

27. Campbell MJ, Swinscow TDV. Correlation and regression. In: Statistics at Square One. 11th edition. Wiley-Blackwell; 2009. p. 119-32.

28. Meng X, Rosenthal R, Rubin DB. Comparing correlated correlation coefficients. Psychol Bull. 1992;111:172-5.

29. Song $M$, Yue $Y$, Jin $Y$, Guo J, Zuo L, Peng H, et al. Intravoxel incoherent motion and ADC measurements for differentiating benign from malignant thyroid nodules: utilizing the most repeatable region of interest delineation at 3.0 T. Cancer Imaging. 2020:20:9.

30. DeLong ER, DeLong DM, Clarke-Pearson DL. Comparing the areas under two or more correlated receiver operating characteristic curves: a nonparametric approach. Biometrics. 1988:44:837-45.

31. Mandrekar JN. Receiver operating characteristic curve in diagnostic test assessment. J Thorac Oncol. 2010;5:1315-6.

32. Wetscherek A, Stieltjes B, Laun FB. Flow-compensated intravoxel incoherent motion diffusion imaging: flow-compensated IVIM diffusion imaging. Magn Reson Med. 2015;74:410-9.

33. Miles KA. Perfusion CT for the assessment of tumour vascularity: which protocol? Br J Radiol. 2003;76 Spec No 1:S36-42.

34. Schneeweiß S, Horger M, Grözinger A, Nikolaou K, Ketelsen D, Syha R, et al. CT-perfusion measurements in pancreatic carcinoma with different kinetic models: is there a chance for tumour grading based on functional parameters? Cancer Imaging. 2016;16:43.

35. Klauß M, Stiller W, Pahn G, Fritz F, Kieser M, Werner J, et al. Dual-energy perfusion-CT of pancreatic adenocarcinoma. Eur J Radiol. 2013;82:208-14.

36. Lemke A, Stieltjes B, Schad LR, Laun FB. Toward an optimal distribution of $b$ values for intravoxel incoherent motion imaging. Magn Reson Imaging. 2011;29:766-76

37. Goh V, Halligan S, Daley F, Wellsted DM, Guenther T, Bartram Cl. Colorectal tumor vascularity: quantitative assessment with multidetector CT--do tumor perfusion measurements reflect angiogenesis? Radiology. 2008;249:510-7.

38. Miles KA. Tumour angiogenesis and its relation to contrast enhancement on computed tomography: a review. Eur J Radiol. 1999:30:198-205.

39. Katsuta E, Qi Q, Peng X, Hochwald SN, Yan L, Takabe K. Pancreatic adenocarcinomas with mature blood vessels have better overall survival. Sci Rep. 2019;9:1310.

40. Lemke A, Laun FB, Klauss M, Re TJ, Simon D, Delorme S, et al. Differentiation of pancreas carcinoma from healthy pancreatic tissue using multiple bvalues: comparison of apparent diffusion coefficient and intravoxel incoherent motion derived parameters. Investig Radiol. 2009:44:769-75.

41. Klauß M, Stiller W, Fritz F, Kieser M, Werner J, Kauczor H-U, et al. Computed tomography Perfusion analysis of pancreatic carcinoma. J Comput Assist Tomogr. 2012;36:237-42.

42. Li H, Sun C, Xu Z, Miao F, Zhang D, Chen J, et al. Low-dose whole organ CT perfusion of the pancreas: preliminary study. Abdom Imaging. 2014;39:40-7.

\section{Publisher's Note}

Springer Nature remains neutral with regard to jurisdictional claims in published maps and institutional affiliations. 